\title{
Para além do humor e do sexo: hierarquias em negociação
}

Beyond Humor and Sex: Hierarchies Under Negotiation

Lerice de Castro Garzoni *

SCHETTINI, Cristiana. Clichês baratos: sexo e humor na imprensa ilustrada carioca do início do século XX. Campinas: Editora da Unicamp, 2020.

Em busca de diversão noturna, homens que viviam no Rio de Janeiro do início do século XX encontravam inúmeras opções de entretenimento no centro da cidade. Teatros, cinematógrafos, casas de chope e jardins são apenas alguns exemplos, dentre tantos outros locais de sociabilidade masculina. Não raro, nesses espaços, elementos relacionados ao sexo e ao humor eram mobilizados para atrair e satisfazer os anseios de uma ampla e diversificada clientela. "Estrangeiros no tempo", leitoras e leitores de Clichês Baratos: sexo e humor na imprensa carioca do início do século XX, novo livro de Cristiana Schettini, iniciam seu percurso por esse mundo com um passeio que reproduz roteiros disponíveis a muitos consumidores desse lazer repleto de apelos eróticos. As perspectivas masculinas, porém, estão longe de serem as únicas, tampouco as mais enfatizadas pela historiadora.

Doutora em História pela Universidade Estadual de Campinas (UNICAMP), a autora fez uma tese sobre a prostituição carioca no início do período republicano. Esse trabalho foi premiado pelo Arquivo Nacional e deu origem ao livro "Que tenhas teu corpo": uma história social da prostituição no Rio de Janeiro das primeiras décadas republicanas, publicado em 2006. Desde então, ela tem se dedicado a pesquisas sobre o tema e sobre imigração no Brasil e na Argentina, com ênfase na perspectiva de gênero. Publicou inúmeros artigos e organizou coletâneas, sendo a mais recente em parceria com Juan Suriano,

\footnotetext{
* Instituto Federal de Educação, Ciência e Tecnologia do Sul de Minas Gerais (IFSULDEMINAS), Poços de Caldas, MG, Brasil. lerice.garzoni@gmail.com <https://orcid.org/0000-0002-4858-520X>
} 
intitulada Historias Cruzadas: diálogos historiográficos sobre el mundo del trabajo en Argentina y Brasil (2019). Atualmente, leciona no Instituto de Altos Estudios Sociales da Universidade Nacional de General San Martín (USAM) e é pesquisadora do Consejo Nacional de Investigaciones Científicas y Técnicas (CONICET).

Em Clichês Baratos, para mostrar como a "mercantilização das diversões" é um objeto profícuo em uma pesquisa no campo da História Social, a autora volta-se para a imprensa de humor sexual, mais especificamente, para a trajetória do jornal $\mathrm{O}$ Rio $\mathrm{Nu}$. Esse título, assim como seus congêneres, tinha profundas conexões com esse mercado, caracterizado pela presença de projetos empresariais que compartilhavam as mesmas lógicas de consumo, assim como a circulação de conteúdos e pessoas. Atrizes e prostitutas também estavam presentes naqueles itinerários noturnos, aparentemente sem o mesmo protagonismo que os homens, mas como alvos do desejo (e eventual escárnio) alheio. De forma semelhante, na imprensa citada, representações de corpos femininos parcialmente desnudos e em posições insinuantes eram acompanhadas por histórias em que o foco era a satisfação do prazer masculino.

Mulheres, portanto, ocupavam lugar de destaque, tanto na vida noturna quanto nas páginas da referida imprensa. Porém, sua presença tinha como objetivo agradar espectadores, clientes e leitores. À primeira vista, tratava-se de uma visibilidade silenciada, sem permitir que expressassem suas próprias visões e demandas. Sem negar a centralidade da objetificação feminina, a autora defende que é possível efetuar uma análise que revele como "homens e mulheres negociavam as hierarquias sociais e morais" (Schettini, 2020), objetivo plenamente alcançado ao longo dos seis capítulos do livro, que, disponível apenas em formato digital, apresenta abundância de ilustrações, além de áudios, mapas e vídeo.

Negociação é uma concepção central ao longo de toda a pesquisa que, analisando e contrapondo diferentes fontes históricas a partir de $\mathrm{O} R i o \mathrm{Nu}$, e inserindo-as em um consistente debate com estudos anteriores, consegue identificar as ações de sujeitos históricos naquele contexto específico. Se incontáveis marcas de exclusão social existiam no Rio de Janeiro do período, caracterizado pela segregação urbana, por uma república autoritária e pelos inúmeros conflitos característicos do pós-abolição, essas hierarquias estavam longe de ser simplesmente pré-estabelecidas ou impostas, tampouco eram apenas ide- 
alizadas ou projetadas, mas estavam em constante e intensa negociação, como aponta o estudo.

Assim, os registros são retirados da atemporalidade; deixam de ser vistos como evidências do que autora chama de "uma espécie de machismo eterno" (Schettini, 2020) e passam a fornecer indícios para além da intenção com que foram produzidos. Os clichês que intitulam o volume remetem às imagens estereotipadas e facilmente reproduzidas. No livro, eles são usados para compreender as percepções de diferentes homens e mulheres, as dinâmicas sociais e as possibilidades de ação, mesmo dentro de uma realidade opressora como aquela da capital da recém-instaurada república do Brasil. Na verdade, uma enorme variedade de fontes é empregada de forma estratégica, ora com a interpretação detida de uma única crônica ou fotografia, ora com o mapeamento de um amplo debate que mobilizou grande parte da imprensa carioca ao longo de um período específico.

Além disso, a seleção de citações e imagens para a discussão dos problemas propostos em cada capítulo é extremamente criteriosa, o que permite que leitoras e leitores, especialistas ou não, acompanhem com facilidade a argumentação desenvolvida em uma narrativa leve e intrigante. Toda a documentação é colocada em diálogo com ampla bibliografia nacional e internacional, sendo notável a construção do debate historiográfico, no qual a pesquisa se insere e com o qual visa contribuir. Além das dimensões de gênero, a autora busca mapear como questões de classe e raça se conectam no material estudado, destacando a importância "de uma análise contextual, relacional e histórica" (Schettini, 2020), no lugar de apenas discussões teóricas. Essa postura, mantida ao longo de todo o percurso feito pela autora, faz com que conceitos fundamentais para a disciplina sejam, de fato, operacionalizados no trabalho empírico.

No livro, é possível acompanharmos as trajetórias de homens e mulheres de diferentes origens e cores de pele que, ao investirem em empreendimentos ou carreiras ligados ao mercado de entretenimento que se consolidava naquele momento, estavam elaborando e projetando identidades sobre si mesmos ou sobre os outros, disputando espaços nas páginas da imprensa, no mundo das diversões noturnas, na cidade e na própria república. Ao explorar as interseções entre questões variadas, a publicação colabora, de forma efetiva, com novos questionamentos e pontos de vista para discussões - algumas delas já 
consagradas - sobre cultura popular, classe trabalhadora, racismo, racialização e usos de gênero na Primeira República.

Destina-se, portanto, ao público especializado que tenha interesse pelo período ou pelos temas abordados, assim como às historiadoras e aos historiadores em formação, os quais estejam empenhados em compreender como fazer uma pesquisa, e, especialmente, a todos aqueles que pretendem iniciar ou dar continuidade a estudos que mobilizem a categoria de gênero no campo da História Social. Ao mesmo tempo, a forma de contar histórias de pessoas tão distintas, que passaram por reveses surpreendentes ao tentar moldar seus próprios destinos, também torna a obra instigante para os mais variados leitores.

Os capítulos iniciais exploram os "sentidos das masculinidades", com foco na criação de $O$ Rio $N u$ e no perfil de seus colaboradores. Assim, diferentes documentos são mobilizados para construir o panorama que torna possível a concepção e a proposição do periódico, que se identifica como humorístico e malicioso. Nesse momento do livro, chama atenção a escolha da autora em não apresentar a literatura pornográfica como parte desse cenário que antecede a estreia de $\mathrm{O}$ Rio $\mathrm{Nu}$. Porém, ao longo da publicação, uma série de apontamentos e contraposições entre o periódico e essa literatura, no que tange à circulação, ao conteúdo e ao público almejado, é realizada. Isso deixa evidente que, ao abandonar esse lugar-comum como ponto de partida da análise, as especificidades do jornal são problematizadas de forma mais consistente e aprofundada.

Desconfiando do discurso despretensioso de seus fundadores, que sugerem que o início da publicação teria sido um "arroubo de juventude", a autora observa os projetos mais ou menos explícitos que estão por trás de $\mathrm{O}$ Rio $\mathrm{Nu}$, e que envolvem não apenas demandas comerciais, mas também a possibilidade de se alcançar distinção social. Por meio da reunião de informações breves e esparsas, a historiadora consegue mapear as conexões entre essa imprensa, o mundo político e o associativismo operário, mostrando como a invenção de uma masculinidade boêmia e viril foi central para criar uma identidade comum a homens muito diversos entre si. A trajetória de um desses fundadores e o escrutínio dos "tipos masculinos" divulgados na imprensa ajudam a aprofundar essas questões, além de refletir sobre "processos de racialização" que se relacionam ao ingresso desses sujeitos no mundo das letras e na vida mundana.

Os capítulos seguintes abordam como a identidade de $\mathrm{O}$ Rio $\mathrm{Nu}$ se define e se transforma, com destaque para a importância das ilustrações e para a 
ampla e incômoda circulação do periódico. O esforço em se afirmar como malicioso, mas não pornográfico ou obsceno, foi fundamental para que o periódico se apresentasse como um tipo específico de humor sexual, associado à elegância e à modernidade. A autora consegue identificar e classificar diferentes imagens e sua importância para a identidade da folha. Assim, enquanto a participação de artistas locais, conhecidos ou anônimos, acentuava a crítica social e política, a adaptação de desenhos da imprensa internacional enfatizava as conotações sexuais, algo ainda mais acentuado com a introdução das fotografias.

Embora mencione a dificuldade de rastrear as ilustrações estrangeiras, sua origem e autoria, a historiadora consegue colocar, lado a lado, algumas capas originais e as adequações feitas para o Rio $\mathrm{Nu}$, interpretando os sentidos da produção e da apropriação desses clichês. Nesse ponto, a acuidade da seleção e da interpretação suscita a curiosidade, entre os aprendizes do ofício, sobre os bastidores da pesquisa; ou seja, sobre como ocorreu a busca por essas fontes e a ideia de contrapô-las de uma forma tão acessível e imprescindível ao texto. Para o público mais amplo, por sua vez, essas comparações aprofundam a compreensão sobre a importância da crítica documental, procedimento imprescindível para os historiadores.

Tomando como ponto de partida uma campanha iniciada por um grupo de católicos para restringir a circulação do jornal, visto como ameaça à moral, a autora discute o incontrolável "avanço comercial da cultura visual erótica", assim como as constantes negociações em torno dos limites da moralidade. Essa campanha também esteve relacionada ao lançamento da revista Sans Dessous, cuja análise revela uma ênfase no erotismo e um maior destaque para a vida elegante. Colocar os periódicos em conjunto ajuda a compreender as interlocuções que estabelecem, assim como suas diferenças, constatando como se iluminam mutuamente no conjunto das diversões noturnas.

Os dois últimos capítulos são os mais surpreendentes, pois é bastante desafiador buscar aspectos da experiência social das mulheres em periódicos que, produzidos e consumidos por homens, retratavam corpos femininos brancos e genéricos, estrategicamente posicionados para satisfazê-los. Como ler esse material e conseguir dar visibilidade aos múltiplos usos dessa imprensa pelas mulheres, de forma tão sofisticada e complexa, a exemplo do que foi feito em relação às masculinidades? Partindo das leitoras idealizadas e daque- 
las reais, presentes nas seções de fofocas e de concursos, Cristiana Schettini mostra a centralidade, nessas folhas, das mulheres envolvidas no comércio sexual, assim como a forma como tais mulheres negociavam suas próprias imagens.

Assim, aspectos da vida e do trabalho de Alice, Augusta e Marietta vêm à tona, sobretudo suas percepções, anseios e tentativas de controlar seus negócios e destinos. Reconhecendo os "vários imponderáveis", mas sem deixar que eles inviabilizem as leituras possíveis, a autora mobiliza variados casos para fundamentar suas descobertas a respeito dessas mulheres, que não são vistas ou tratadas como excepcionalidades. Sans Dessous - bem como as fotografias que ele realizou com a sua própria "Kodak", pensadas em conjunto com as seções de $\mathrm{O}$ Rio $\mathrm{Nu}$-, ajuda-nos a entender que essas imagens não serviam apenas aos desejos e propósitos masculinos, mas também àqueles de trabalhadoras desse mercado de entretenimento.

O título teve apoio da Fundação de Amparo à Pesquisa do Estado de São Paulo (FAPESP) e faz parte da Coleção Históri@ Ilustrada, da Editora da Unicamp, que publica livros digitais ricos em documentos textuais, iconográficos e sonoros. Viabilizar o acesso direto às fontes, colocando o suporte a serviço do trabalho acadêmico, é uma das propostas de toda a coleção, com vistas a atrair audiências variadas, o que pode ser caracterizado como uma tarefa árdua e urgente em tempos de debates sobre o que é fazer História e sobre o ofício do historiador enquanto profissão.

Em Clichês baratos, a ampla disponibilização de documentos tão diversos entre si cumpre todos esses propósitos, além de explorar novas possibilidades de análise decorrentes dessa exposição, com questionamentos, por exemplo, a respeito da "execução dos gestos, tons e movimentos sobre o palco" (Schettini, 2020), destacando-se o que buscavam enfatizar ou distorcer. Por todas essas características, o livro suscita inquietações necessárias e importantes, tanto entre leitores especializados quanto no público mais amplo. Se o humor sexual do início do século XX desperta curiosidade, a profundidade da análise proposta por Cristiana Schettini permite irmos além, compreendendo as negociações protagonizadas por homens e mulheres na Primeira República. 


\section{REFERÊNCIAS}

SCHETTINI, Cristiana. Clichês baratos: sexo e humor na imprensa ilustrada carioca do início do século XX. Campinas: Editora da Unicamp, 2020.

SCHETTINI, Cristiana. "Que tenhas teu corpo": uma história social da prostituição no Rio de Janeiro das primeiras décadas republicanas. Rio de Janeiro: Arquivo Nacional, 2006.

SURIANO, Juan; SCHETTINI, Cristiana (Compiladores). Historias cruzadas: Diálogos historiográficos sobre el mundo del trabajo en Argentina y Brasil. Buenos Aires: Editorial Teseo, 2019. 